\title{
A MORPHOLOGICAL STUDY OF RABBIT CORNEAS AFTER LASER KERATECTOMY
}

\author{
I. M. RAWE ${ }^{1}$, R. W. ZABEL ${ }^{2}$, S. J. TUFT ${ }^{3}$, V. CHEN ${ }^{2}$, K. M. MEEK ${ }^{1}$ \\ Oxford, Minneapolis and London
}

\begin{abstract}
SUMMARY
We have examined the morphology of the collagen and proteoglycans in rabbit corneas that have undergone excimer laser photorefractive keratectomy using a clinical, $193 \mathrm{~nm}$ excimer laser. The photoablation was carried out to a stromal depth of $100 \mu \mathrm{m}$ and a diameter of $6 \mathrm{~mm}$. All ablated corneas developed a haze that was most intense between week 4 and week 8 and which showed no improvement after week 16. The corneas were stained with the cationic dye cuprolinic blue to visualise proteoglycans and were then processed for transmission electron microscopy. The ultrastructural location of proteoglycans (keratan sulphate and dermatan sulphate) was observed in the corneal wounds at different time intervals. Corneas that had undergone steroid treatment post-operatively were also examined. In the healing tissue proteoglycan filaments of abnormal size were observed, which became most prominent after 2 weeks. As healing progressed these abnormal filaments decreased but after 45 weeks some were still present, indicating that the proteoglycan content had not returned to normal.
\end{abstract}

The excimer laser is currently being evaluated as a tool for altering the refractive properties of the eye by reshaping the anterior curvature of the cornea. This technique, called photorefractive keratectomy (PRK), can remove corneal tissue very accurately by ablation and, it is thought, without causing any thermal damage. It has advantages over manual keratectomy because it leaves a smooth stromal surface which results in better optical properties. Initial studies have shown the efficacy and safety of excimer laser PRK. ${ }^{1}$ Further clinical studies have shown good results; ${ }^{2}$ however, the major problem faced is that of corneal wound healing. ${ }^{3-5}$ This causes a regression of the correction and the formation of a subepithelial haze due to the regeneration of the corneal stromal tissue..$^{6-8}$ The extent of deposition of regenerated tissue is unpredictable, but

From: ${ }^{1}$ The Open University, Oxford Research Unit, Oxford, UK; ${ }^{2}$ University of Minnesota, Minneapolis, Minnesota, USA; ${ }^{3}$ Moorfields Eye Hospital, City Road, London, UK.

Correspondence to: I. M. Rawe, The Open University, Oxford Research Unit, Foxcombe Hall, Berkeley Road, Oxford OX1 5HR, UK. deeper ablations are reported to produce greater corneal opacification. ${ }^{9}$ This has implications for the visual acuity of the treated eye. For PRK to be successful the refractive correction must be predictable and the long-term implications need to be evaluated.

The role of steroids and other antifibrotic agents following PRK is being assessed. ${ }^{10-12}$ Steroid treatment reduces the regeneration of new stromal tissue, possibly by suppressing the fibroblastic response via inhibition of DNA and protein synthesis in the stromal keratocytes.

The transparency of the corneal stroma is thought to be due to the regular spacing and narrow, uniform diameter of the collagen fibrils. ${ }^{12}$ Corneal scar tissue is opaque due to its decreased ultrastructural order. ${ }^{13}$ After an extended period of healing, transparency improves as ultrastructural order improves. ${ }^{14} \mathrm{X}$-ray diffraction studies of full-thickness rabbit corneal scar tissue demonstrate a measurable increase in fibril order between the second and third month of wound healing. ${ }^{15}$

The regular spacing of collagen fibrils in the normal adult stroma is thought to be governed by proteoglycans and by glycoproteins such as type VI collagen. ${ }^{16,17}$ Proteoglycans are hybrid molecules, consisting of a protein to which are attached long chains of highly sulphated repeating disaccharides called glycosaminoglycans (GAGs). The GAGs characteristic of the adult cornea are keratan sulphate and dermatan sulphate. Each molecule of GAG is extremely hydrophilic and combines with a great number of molecules of water. Proteoglycans in the cornea have been shown to be distributed evenly between the collagen fibrils and to interact with the fibrils at specific axial locations. ${ }^{18,19}$ This regularity leads to a uniform swelling pressure exerted by the GAGs on the individual collagen fibrils which in turn influences the relative proportions of intra- and interfibrillar water. ${ }^{20}$ Type VI collagen filaments have been shown to be located between collagen fibrils ${ }^{17}$ and are thought to interact with proteoglycans, and therefore also to play an important role in maintaining fibril separation and transparency.

In the early stages of wound healing the GAGs are 
abnormal and have been shown to consist of a highly sulphated, high iduronic-acid-containing dermatan sulphate $^{21}$ with negligible levels of keratan sulphate., ${ }^{3,22}$ Previous studies using the cationic dye cuprolinic blue on full-thickness wounds ${ }^{22}$ and on manual superficial anterior keratectomy wounds ${ }^{23}$ have shown the presence of abnormally large proteoglycan filaments in the early stages of healing. In this study we have used the cationic dye cuprolinic blue to look at the morphology of the healing stromal tissue of excimer laser PRK corneas of rabbits from 1 week to 45 weeks after surgery. Selected corneas underwent steroid treatment with fluorometholone.

\section{MATERIALS AND METHODS}

The Dutch belted rabbits used in this study weighed between 1 and $2 \mathrm{~kg}$. This weight corresponds to an age of approximately 3 months. Thirty rabbits were used, three of which received topical steroid post-operatively. Laser ablations were performed with the animal under general anaesthetic (intramuscular ketamine hydrochloride $100 \mathrm{mg} / \mathrm{ml}$ (Aveco Inc, Fort Dodge, IA) and xylazine $20 \mathrm{mg} / \mathrm{ml}$ (Mobay Corporation, Shawnee, OL)) and topical (Acaine) anaesthetic.

Each rabbit was positioned to ensure proper alignment within the operative plane of the laser (Taunton Technologies, Monro). A circular impression was made in the corneal epithelium using an $8 \mathrm{~mm}$ optical zone marker centred on the pupil and the contained epithelium was gently removed using a Tooke knife. A stromal wound with a 'top hat' profile, $100 \mu \mathrm{m}$ in depth and $6 \mathrm{~mm}$ in diameter, was ablated at a fluence measured at the operative plane of $125 \mathrm{~mJ} / \mathrm{cm}^{2}$. The laser was operated at $10 \mathrm{~Hz}$. Effluent was removed using a vacuum suction device. While the animal was anaesthetised the eyes were taped shut to prevent corneal drying. Gentamycin $0.3 \%$ drops were instilled twice daily for 1 week. Selected eyes received topical fluorometholone four times daily for 5 weeks.

Epithelialisation of the eyes was complete within 1 week. The rabbits were killed at intervals of $1,2,4,8,16$, 35 and 45 weeks, and rabbits that had undergone steroid treatment at 15, 35 and 45 weeks, under full general anaesthetic using intravenous T-61 euthanasia solution (Hoechst-Roussel, Somerville, NJ). Broad-beam slit lamp photography was performed prior to the animals being killed. The corneas were excised and frozen in liquid nitrogen. Tissue was stored at $-70{ }^{\circ} \mathrm{C}$ until processed. For processing, the central region was isolated and cut into approximately $1.0 \mathrm{~mm}^{2}$ sections which were then immersed in $0.05 \%$ cuprolinic blue stain (BDH Ltd, Atherstone, Warwickshire, UK) containing $2.5 \%(\mathrm{w} / \mathrm{v})$ glutaraldehyde and $0.1 \mathrm{~mol} / 1 \mathrm{MgCl}_{2}$ in $25 \mathrm{mmol} / 1$ sodium acetate buffer. They were rinsed three times each for 15 minutes in the buffer solution containing no cuprolinic blue and then counterstained using $3 \times 15$ minute changes of aqueous $0.5 \%$ sodium tungstate. This was followed by déhydration through an ethanol series and transfer to propylene oxide before embedding in Polarbed. Sections approximately $90-100 \mathrm{~nm}$ thick were cut on a ReichertJung Ultracut $E$ ultramicrotome and stained in $2 \%$ uranyl acetate before examination with a Philips 301 electron microscope.

\section{RESULTS}

\section{Normal Cornea}

The corneal stroma consists of parallel collagen fibrils in a layered arrangement of lamellae. Proteoglycan staining with cuprolinic blue reveals small filaments between the collagen fibrils. A proportion of these are arranged regularly along the individual collagen fibrils and run cross-

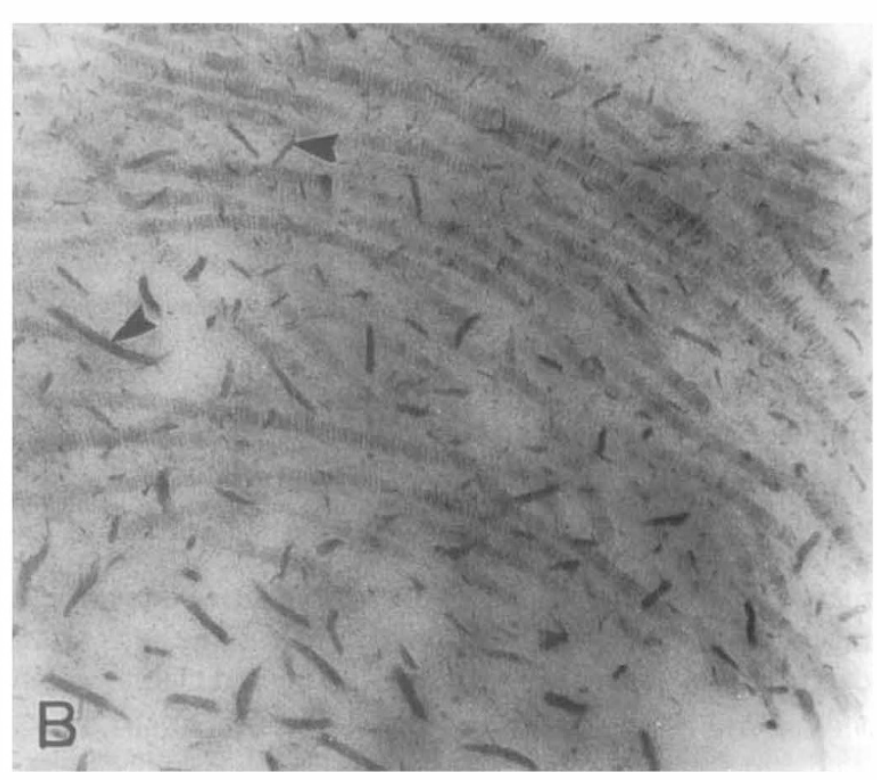

Fig. 1. (A) In normal corneal stroma the collagen fibrils are arranged parallel to one another; small proteoglycan filaments are situated between the collagen fibrils (arrowheads). (B) In healing tissue 2 weeks after wounding many of the small proteoglycan filaments are absent, and the tissue contains proteoglycanfilaments of abnormal size (arrowheads) between disordered collagen fibrils (Stained with cuprolinic blue and counterstained with uranyl acetate. (A) and $(B) \times 60000$.$) .$ 


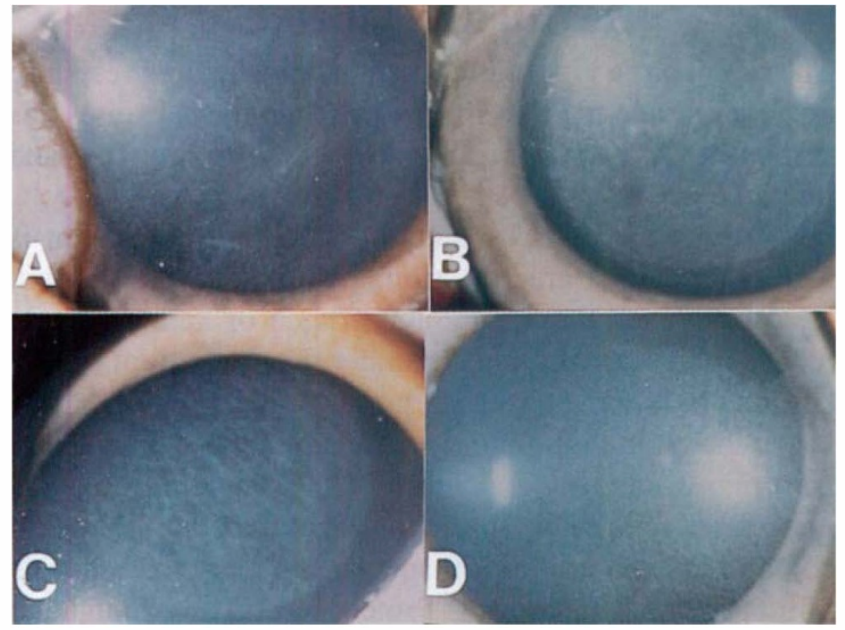

Fig. 2. Photography of the corneal haze present at 1 week $(A)$, 4 weeks $(B)$ and 16 weeks $(C)$ after wounding. At 15 weeks the corneal haze of a cornea treated with steroid $(D)$ is less than that of an untreated cornea of equivalent healing age $(C)$.

wise from one fibril to its neighbour. The rest of the filaments appear to be randomly located (Fig. 1A).

\section{Laser-Ablated Corneas}

Slit lamp examination demonstrated that a corneal haze had developed in all the ablated corneas. This haze was most intense between week 4 and week 8 and showed no improvement after week 16 (Fig. 2B, C). In steroidtreated corneas the corneal haze was less intense compared with the untreated corneas of the equivalent age (Fig. 2D).

Ultrastructural examination after 1 week of healing showed an increased population of keratocytes immediately below the epithelium. Primarily near to and around these keratocytes were areas free of extracellular matrix or vacuoles in the tissue (Fig. 3A). Abnormally large proteoglycan filaments were associated with these vacuoles and amorphous material was present, mostly associated with the proteoglycan filaments (Fig. 3B). Keratocytes further below the epithelium had smaller vacuoles around them and fewer large proteoglycans. The general structure of the stromal tissue suggested that very little new collagen synthesis had taken place.

At 2 weeks of healing there were abundant larger areas free of collagen, which strongly indicated that the tissue at this stage was very hydrated (Fig. 4A). A broader and larger population of abnormally large proteoglycan filaments was seen (Fig. 4B); many of these proteoglycans were associated with the areas free of collagen. Compared with 1 week of healing, when little newly synthesised collagen was seen, at this stage (week 2) there was a greater quantity of newly synthesised collagen fibrils. Some fibrils were in bundles but there were also many individual ones. The small proteoglycans associated with collagen fibrils in normal corneal tissue (Fig. 1A) were reduced in number or absent from many of the collagen fibrils (Fig. 1B) of 2-week-old wound-healing tissue.

After 4 weeks of healing the vacuolated areas in the tis- sue were reduced in number but still present (Fig. 5A), along with the large abnormal proteoglycan filaments (Fig. 5B) - although these filaments appeared to be finer than at week 2. As at earlier stages, many of the vacuolated areas were associated with the keratocytes in the tissue.

This pattern of decreasing numbers of abnormal proteoglycan filaments along with fewer areas free of extracellular matrix continued through the next stages of wound healing (weeks 8 and 16). At the later stages (weeks 35 and 45) scar tissue could still be differentiated
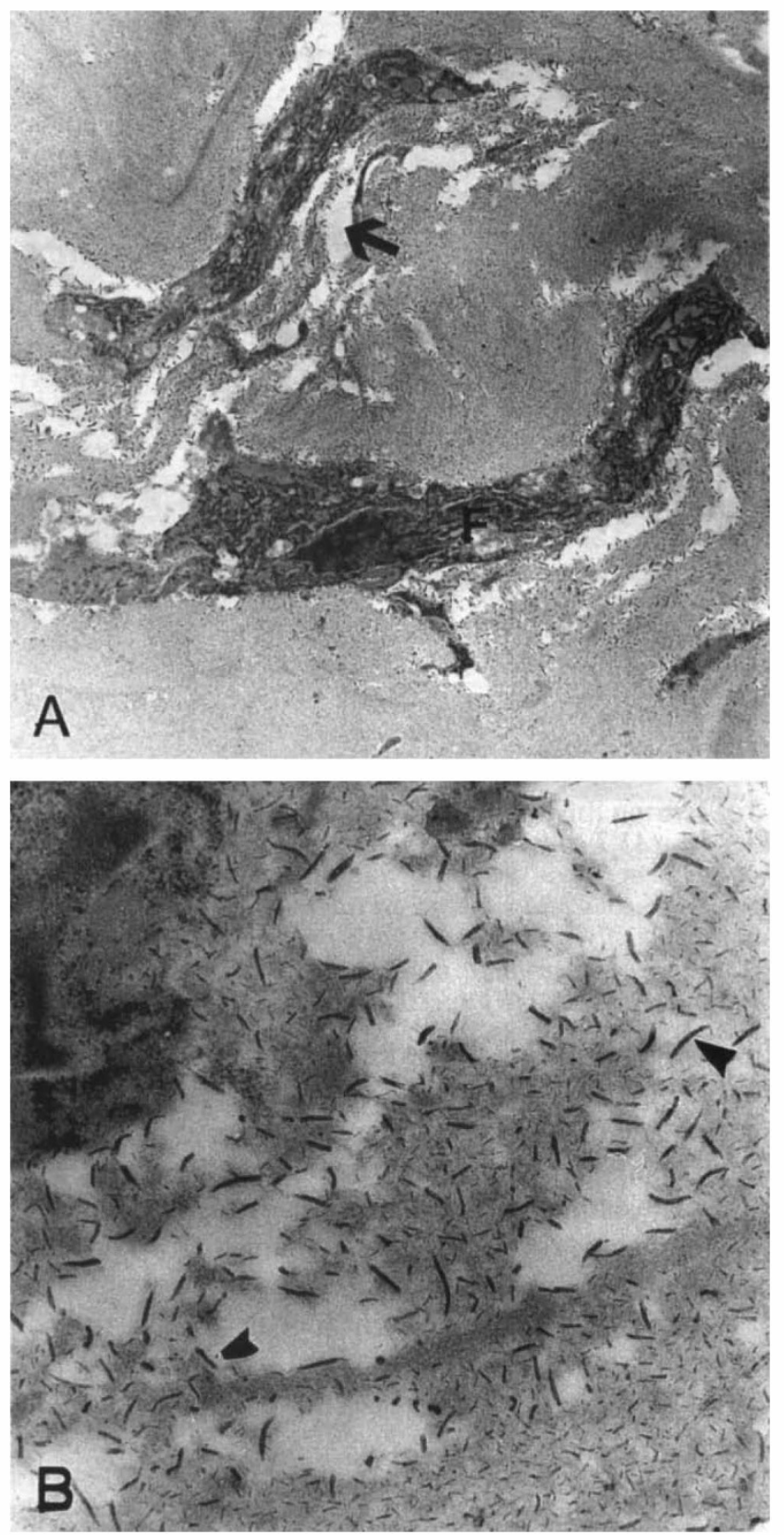

Fig. 3. (A) One-week-old laser keratectomy scar tissue. The stromal fibroblasts $(F)$ under the epithelium have areas free of extracellular matrix closely associated with them (arrow). (B) These matrix-free areas contain abnormal large proteoglycan filaments (arrowhead). (Stained with cuprolinic blue and counterstained with uranyl acetate. $(A) \times 5000 ;(B) \times 30$ 000.) 

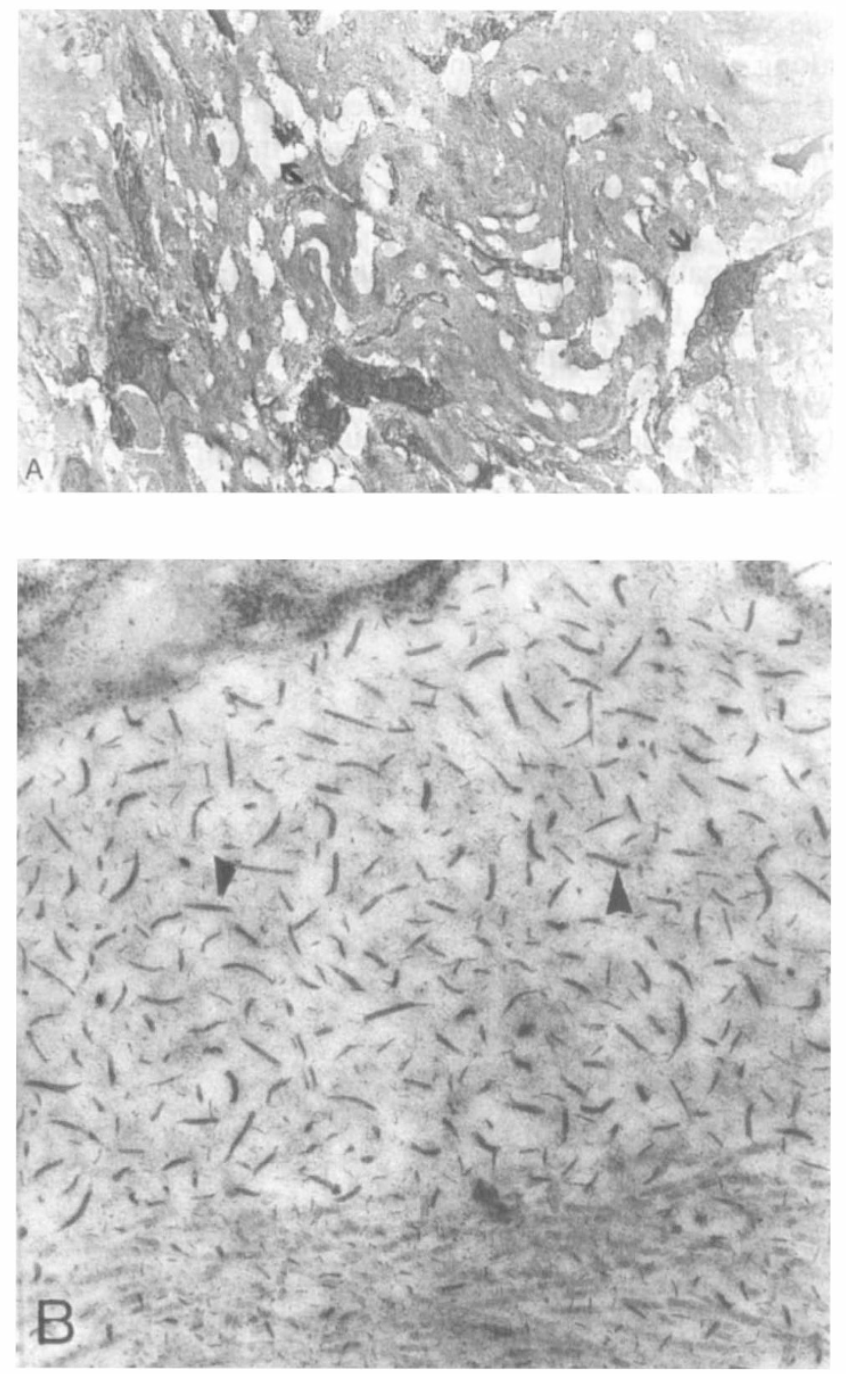

Fig. 4. (A) Two-week-old laser keratectomy scar tissue. As healing progresses, the areas free of extracellular matrix are more numerous and widespread (arrows). (B) The abnormalsized proteoglycan filaments have proliferated (arrowheads). (Stained with cuprolinic blue and counterstained in uranyl acetate. (A) $\times 2400 ;(B) \times 30000$.)

from original stroma by the level of order observed in the tissue (Fig. 6B). There was a wider range of interfibrillar spacing and no well-defined lamellar structure in the scar tissue compared with normal stroma (Fig. 6A, B). Proteoglycan staining in the extracellular matrix appeared to be normal; however, larger filaments could still occasionally be seen within the matrix. Areas containing groups of proteoglycan filaments not associated with collagen persisted in the scar tissue even after prolonged healing (Fig. 6C).

\section{Steroid-Treated Corneas}

After 15 weeks of healing the steroid-treated corneas contained large proteoglycans and areas free of extracellular matrix similar to those observed after 16 weeks of healing in untreated corneas. At the later stages (35 and 45 weeks) steroid-treated corneas contained some abnormal proteoglycans both within the scar tissue matrix and also clustered in areas free of collagen.

\section{DISCUSSION}

The rabbit has a vigorous corneal wound healing response and excimer laser PRK, like other techniques, excites this response. A similar response occurs in monkey and human corneas but to a lesser degree. ${ }^{3}$

By this regenerative reaction to ablation the rabbit is restoring the lost area of stroma. In the stroma, the first step in regeneration is the appearance of keratocytes in higher than normal numbers under the epithelium. These keratocytes then appear to produce, by their location, larger than normal proteoglycan filaments associated with amorphous, densely stained material. The nature of this material is unknown, although scar tissues are known to contain large amounts of specialised proteins such as fibronectin and tenascin. ${ }^{24}$ Proteoglycans are thought to play a role in controlling corneal hydration and these abnormally large filaments may increase the hydration around the keratocytes and result in the areas free of extracellular matrix observed next to and near these cells. As little or no new collagen synthesis was seen at this stage, the production of large proteoglycan filaments may be one of the first steps in stromal regeneration.

A dramatic change in the morphology of the healing tissue occurs by the second week of healing: the distribution, number and size of the abnormal proteoglycan filaments all increase. Newly synthesised collagen can be clearly seen and the tissue contains more areas free of extracellular matrix. Other workers have shown that corneal scar tissue has its highest hydration value 2 weeks after wounding. ${ }^{13,14}$ The over-hydration of this healing tissue might facilitate the deposition of collagen bundles, the passage of cells through the tissue and the removal of breakdown products.

It has been postulated that proteoglycans play a role in collagen fibril development by controlling fibril diameters. ${ }^{25,26}$ We observed that the small proteoglycan filaments closely associated with collagen fibrils in normal cornea are absent between the fibrils within early healing tissue. However, the collagen fibrils in the healing tissue appear to be of approximately normal diameter (Fig. 1B). This suggests that proteoglycans do not play a role in governing the diameter of collagen fibrils. As the age of the healing tissue advances, the numbers of large abnormal filaments decrease and there is also a corresponding reduction in the number and size of the spaces within the matrix.

The haze clinically associated with corneal scar formation is thought to derive from the structural features of the scar tissue. There are three factors to consider. According to Benedek, ${ }^{27}$ when a cornea swells some of the water imbibed goes into 'lakes', that is, areas devoid of collagen fibrils. These lakes may occur within or between the stromal lamellae. When the size of such a region reaches approximately half the wavelength of light (approximately $250 \mathrm{~nm}$ ) it will scatter light and the tissue will start to appear cloudy. The persistence of such lakes in regenerated tissue, even after 45 weeks of healing (Fig. 6C), suggests that they might be responsible for at least some of the 

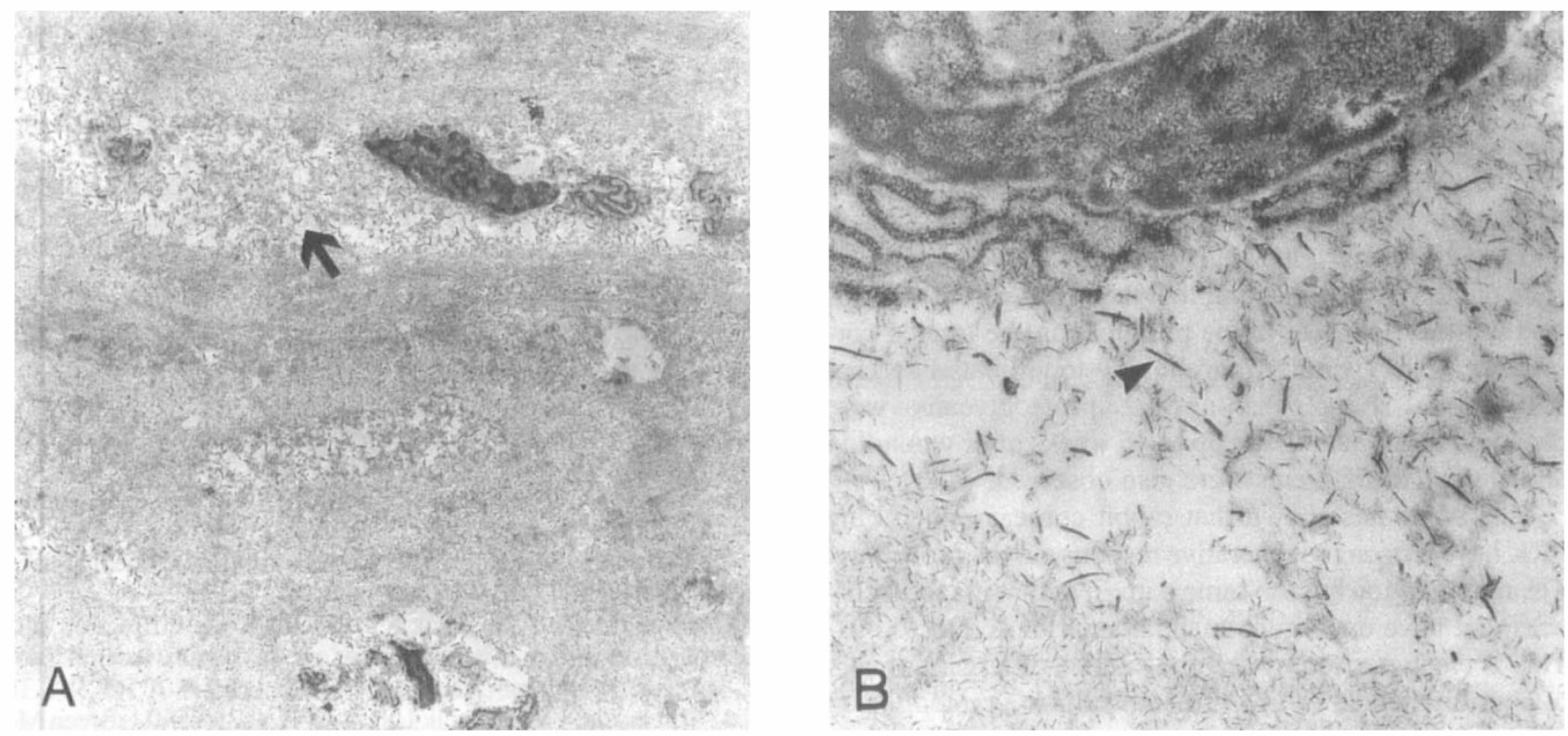

Fig. 5. (A) Four-week-old laser keratectomy scar tissue contains areas free of extracellular matrix (arrow). (B) Proteoglycan filaments (arrowhead) of abnormal size are still present, many located in the areas free of extracellular matrix. (Stained with cuprolinic blue and counterstained with uranyl acetate. $(A) \times 5000 ;(B) \times 30000$.)

corneal haze. The second factor to consider is the corneal lamellae themselves. Certainly in scar tissue there appears to be no layering of the collagen fibrils into lamellae. However, the presence of lamellae is thought not to be required for transparency ${ }^{28}$ and the optical purpose of these structures is not understood. The third, and perhaps the most important, structural difference between corneal scar tissue and normal stroma is the reduction in the degree of ordering of the collagen fibrils. Proteoglycans are thought to play a major role in the transparency of the cornea by maintaining interfibrillar spacing. The proteoglycan arrangement in corneal scar tissue produced by excimer laser keratectomy still contains proteoglycan filaments not seen in a normal stroma. There are larger-thannormal filaments distributed in the matrix in addition to the groups or clumps of proteoglycans, even at 45 weeks after wounding. The larger-than-normal filaments in the scar tissue matrix may stimulate the corneal keratocytes to continue remodelling the tissue, since turnover of scar tissue occurs at an elevated rate compared with normal stro-

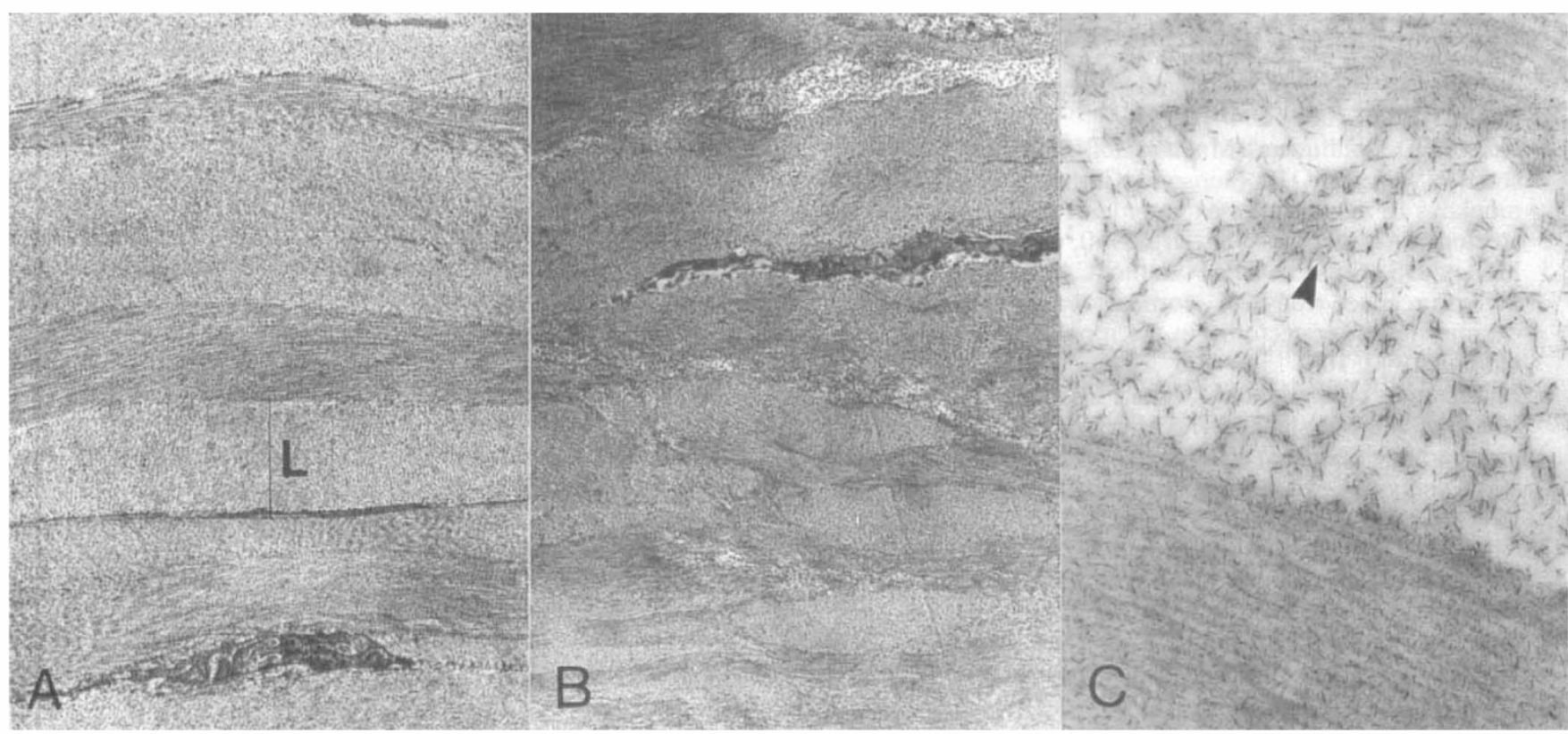

Fig. 6. (A) Normal corneal stroma consists of lamellae $(L)$ containing ordered collagen fibrils. (B) In 45-week-old laser keratectomy scar tissue the collagen fibrils are not organised into well-defined lamellae. (C) Furthermore, in scar tissue groups of proteoglycans (arrowhead) exist not associated with a collagen matrix. (Stained with cuprolinic blue and counterstained with uranyl acetate. (A) and
$(B) \times 5000 ;(C) \times 30000$.) 
mal collagen turnover. ${ }^{22}$ The presence of clumps of proteoglycan filaments may be an indication that remodelling of the scar tissue is still occurring.

Steroids are thought to act by inhibiting the fibroblastic response by blocking DNA and protein synthesis. In this study the corneas treated with steroid during healing had a decreased amount of corneal haze compared with untreated corneas of the equivalent age. However, corneal haze did develop, indicating that the action of the steroids was limited. The scar tissue produced in the treated corneas had a very similar morphology to untreated corneal scar tissue. Larger-than-normal proteoglycans were observed in the scar tissue up to 45 weeks after wounding and clumps of filaments were also observed.

This study has shown that rabbit corneas undergoing PRK have a strong regenerative response to the procedure. The regeneration has the same pattern as that in rabbit corneas that have undergone manual anterior keratectomy. ${ }^{20}$ This is characterised by the appearance of large numbers of abnormal chondroitin/dermatan sulphate proteoglycan filaments seen mainly in the first weeks of healing and by the nature of the scar tissue itself.

I. M. Rawe is a Pharmacia Research Student at the Open University. We gratefully acknowledge financial support of our corneal work by MRC, the Wellcome Trust and the TFC Frost Charitable Trust.

Key words: Collagen, Excimer, Laser, Proteoglycan.

\section{REFERENCES}

1. McDonald MB, Frantz JM, Klyce SD, Beuerman RW, Varnell R, Munnerlyn CR, et al.: Central photorefractive keratectomy for myopia: the blind eye study. Arch Ophthalmol 1990, 108: 799-808.

2. Zabel RW, Sher NA, Ostrov CS, Parker P, Lindstrom RL: Myopic excimer laser keratectomy: a preliminary report. Refract Corneal Surg 1990, 6: 329-34.

3. SundarRaj N, Geiss MJ, Fantes F, Hanna K, Anderson SC, Thompson KP, et al.: Healing of excimer ablated monkey corneas: an immunohistochemical evaluation. Arch Ophthalmol 1990, 108: 1604-10.

4. Hanna KD, Pouliquen YM, Savoldelli M, Fantes F, Thompson KP, Waring GO III, Samson J: Corneal wound healing in monkeys 18 months after excimer laser photorefractive keratectomy. Refract Corneal Surg 1990, 6: 340-5.

5. Malley DS, Steinert RF, Puliafito CA, Dobi ET: Immunofluorescence study of corneal wound healing after excimer laser keratectomy in the monkey eye. Arch Ophthalmol 1990, 108: 1316-22.

6. Lohmann L, Timberlake GT, Fitzke F, Gartry DS, Muir MK, McHugh JD, Marshall J: The effect of changes in corneal transparency on visual acuity after photorefractive keratectomy using an excimer laser. Invest Ophthalmol Vis Sci 1991, 32: 721.

7. Klyce SD, Wilson SE, McDonald MB, Liu JC, Kaufman HE: Corneal topography after excimer laser keratectomy. Invest Ophthalmol Vis Sci 1991, 32: 721.
8. Seiler T, Jean B, Pham T, Derse M, Bende T: Statistical analysis of myopic regression after excimer laser PRK. Invest Ophthalmol Vis Sci 1991, 32: 721.

9. Taylor DM, L'Esperance FA, Del Pero RA: Human excimer laser lamellar keratectomy. Ophthalmology 1989, 96: 654-63.

10. Talamo JH, Gollamudi S, Green WR, De La Cruz Z, Filatov V, Stark WJ: Modulation of corneal wound healing after excimer laser keratomileusis using topical mitomycin $\mathrm{C}$ and steroids. Arch Ophthalmol 1991, 109: 1141-6.

11. Tuft SJ, Zabel RW, Marshall J: Corneal repair following keratectomy: a comparison between conventional surgery and laser photoablation. Invest Ophthalmol Vis Sci 1989, 30: 1769-77.

12. Maurice DM: The structure and transparency of the corneal stroma. J Physiol 1957, 136: 263-86.

13. Cintron C, Schneider, H, Kublin CL: Corneal scar formation. Exp Eye Res 1973, 17: 251-9.

14. Cintron C and Kublin CL: Regeneration of corneal tissue. Dev Biol 1977, 61: 346-57.

15. Rawe IM, Tuft SJ, Meek KM, et al.: X-ray diffraction and electron microscope studies of rabbit corneal scar tissue. Invest Ophthalmol Vis Sci 1991, 32: 1164.

16. Borcherding MS, Blacik LS, Sittig RA, Bizzel JU, Breen M: Proteoglycans and collagen fibre organisation in human cornea scleral tissue. Exp Eye Res 1975, 21: 59-70.

17. Cho H, Covington HI, Cintron C: Immunolocalization of Type VI collagen in developing and healing rabbit cornea. Invest Ophthalmol Vis Sci 1990, 31: 1096-102.

18. Scott JE and Haigh M: Proteoglycan-Type 1 collagen interactions in bone and non-calcifying connective tissues. Biosci Rep 1985, 5: 71-81.

19. Meek KM, Elliott GF, Nave CA: Synchrotron X-ray diffraction study of bovine cornea stained with cupromeronic blue. Coll Relat Res 1986, 6: 203-18.

20. Katz EP, Wachtel EJ, Maroudas A: Exrafibrillar proteoglycans osmotically regulate the molecular packing of collagen in cartilage. Biochim Biophys Acta 1986, 882: 136-9.

21. Funderburgh JL and Chandler JW: Proteoglycans of rabbit corneas with nonperforating wounds. Invest Ophthalmol Vis Sci 1989, 30: 435-42.

22. Cintron C, Covington HI, Kublin CL: Morphologic analyses of proteoglycans in rabbit corneal scars. Invest Ophthalmol Vis Sci 1990, 31: 1789-97.

23. Rawe IM, Tuft SJ, Meek KM: Proteoglycan and collagen morphology in superficially scarred rabbit cornea. Histochem J 1992 24: 311-18.

24. Van Setten G-B, Koch JW, Tervo K, Lang GK, Tervo T, Naumann $\mathrm{GOH}$, et al.: Expression of tenascin and fibronectin in rabbit cornea after excimer laser surgery. Invest Ophthalmol Vis Sci 1991, 32: 1247.

25. Scott JE, Orford CR, Hughes E: Proteoglycan-collagen arrangements in developing rat tail tendon Biochem $J$ 1981, 195: $573-81$.

26. Scott JE: The periphery of developing collagen fibril. Biochem J 1984, 218: 229-33.

27. Benedek GB: Theory of transparency of the eye. Appl Optics 1971, 10: 459.

28. Hart RW and Farrell RA: Light scattering in the cornea. $J$ Opt Soc Am 1969, 59: 766. 